\title{
Current Globalization: A Challenge For The Humanities
}

\author{
Oleg N. Yanitsky \\ Prof. Dr. of Sciences (Philosophy) \\ Chief Researcher, Institute of Sociology \\ Russian academy of sciences
}

\begin{abstract}
Globalization and the New Technological revolution as its driving force challenge the humanities. The growing unfitness between a highly complex and risky globalization process and current short-term and monodisciplinary approach to the study of it is characteristic to the majority of the humanities. To my mind, new object of study, the sociobiotechnical systems (hereafter, the SBT-systems) have emerged in which social, biological and technical structures and processes are highly integrated by various metabolic processes. Therefore, dichotomy approaches like 'man-nature', 'ruralurban', 'we-they', 'here-there' are not fit to integrative character of globalization processes. This gap should be overcome by problem-oriented and interdisciplinary researches taking into account a global-local and multidisciplinary character of ongoing transformations. A view of an insider from any 'focal point' of globalization is as important as the study carried out by an outer observer. The recent development of humanitarian studies and its institutional structure should 'follow the actor' principle, be such actor a rank-and-file, a politician or a state. A 'humanities-technological innovation-social life' interactions should be studied at all levels of the SBT-system functioning and evolution. All in all, the humanities should be gradually modernized.
\end{abstract}

Keywords: epistemology, digitalization, globalization, humanities, problem-oriented and interdisciplinary approach, metabolism, method, modernization, technological revolution, the SBT-system

\section{THE ISSUE}

Globalization based on information-communication technologies (hereafter the ICtechnologies) is the main challenge of our times. Initiating by the new stage of technological revolution, globalization process acquires a systemic character embracing all spheres of natural and social life. Actually, the globalization means the shaping of new mode of production and social order. In turn, these global systemic transformations generate an all-embracing cascade of changes in various spheres of economic, political and social life of the globe as well as of regions, cities, and local communities. The shift from the Second to the Third and now to the Fourth Technological Revolution will generate qualitatively new challenges for the humanities. There is a growing gap between majority of current concepts and field-researches in the humanities focussed on relatively stable structures and relationships and a highly complex, nonlinear and risky globalization process accompanied by the twists, bifurcations, and unintended consequences. Besides, due to the existing institutional and resource restrictions the majority of current research are mainly local (regional) and short-termed ones. In my view, an overall technological development outstrips its comprehension by the humanities and political regulation.

\section{EPISTEMOLOGY AND METHOD}

There is growing unfitness between highly complex, nonlinear and risky globalization process accompanied by twists, bifurcations, and unintended consequences and a majority of current 
studies of it. Besides, due to the existing institutional and resource restrictions the majority of these studies are mainly local (regional) and short-termed. Another urgent issue is a growing inequality in speed development of natural sciences and humanities. For example, every year about 40 new types of synthetic narcotics (bath salts, aromatics, etc.) are invented and disseminated around the world. The speed of comprehension and social politics control of such 'novelty' are far behind. In general, an overall institutional structure of global community, from local to global, is far behind of the natural and technical sciences development. More generally: the community of the humanities is in total dependence on biochemical industry.

Epistemologically, I've maintained three approaches: our planet is an unstable and contradictory system but it is the wholeness with its own mode of behaviour; the nature, man and its technical devices may play a role of an actor or an environment, and a researcher should follow these actors and ongoing transformations. Following U. Beck, I tried to reveal and estimate maximum 'goods' and 'bads', be they of inherent or distant nature, produced in the run of local, regional and global conflicts, etc. The production of 'goods' is as important as production of various wastes [Bauman, 2004]. The analysis of theoretical speculations had been an important part of my epistemology as well. Such analysis had been not an easy task because it had been necessary to screen a growing volume of international journals and books. Nevertheless, such work had been done especially in relation to the leading theorist across the world [Bauman, 2011; 2011a; 2011b; Beck, 1992; 1999; 2007; 2015; Burawoy, 2015; Budyko, 1977; Capra, 1982; Castells, 2010; Catton and Dunlap, 1980; Chizhevskiy, 1926, 1964; FisherKowalski, 1997; Fisher-Kowalski and Haberl, 2007; Giddens, 2009; Ionin; Irwin and Wynne, 1996; Keen, 2008; Martinez-Alier, 2009; Milbrath, 1984; Lidskog et al., 2015; Phillips, 2009; Prigogine and Stengers, 1984; Prades, 1999; Sundar, 2014; Touraine, 1988; Wilenius, 1999; Urry, 2003, 2005, 2008, 2012; Van Holdt, 2014]; Vernadsky, 1980; Waters, 1995; Wolman, 1965]. My previous and recent works in these fields had also been reconsidered [Yanitsky, 1999; 2004; 2012; 2012a; 2013; 2014; 2014a; 2015, 2016].

The current and sometimes very strained the TV and radio discussions in Russia turned very helpful because there were experts, theorists and journalists from Russia, the US, The EU, Germany, Great Britain, Brazil, India, Italy, France, Poland, Ukraine and other countries and their alliances. Historical time distance turned very important, and again my international contacts from mid1950s till now turned rather fruitful. In particular, I'd realised how useful appeared my meetings and talks with Brazilian urban planners and volunteers in 1957-63s. A space-time distance plays a very significant role in comprehension of global changes. The experience of my father who gave the course of lectures titled 'At the map of the globe' (in recent words, it means geopolitics) was rather helpful to me a well. During the period in question I keep a diary which allowed me to trace my theoretical speculations, and to estimate them later critically. In sum, the use of diverse scientific and cultural approaches coupled with permanent discussions with a variety of people across Russia and the globe allowed me to gain more or less stereoscopic and dynamic picture of the evolution of the global SBT-system and its reflection in humanities. Of course, it is only the contours of these interdepended processes. But I'm convinced that this dynamic picture helps us to overcome the gap between the SBTsystem evolutions accelerated by the IC-technologies development and to comprehend it from the humanitarian viewpoint.

\section{Empirical base}

Following the above epistemology, my study has been based on a wide range of research methods and techniques. In particular, that was mid-term comparative problem-oriented and interdisciplinary projects focussed on particular case-studies within the global context; during about 25 years I analysed an activity of grassroots, NGOs and social movements across the 
Europe and Russia; the main international sociological journals like 'The International Social Science Journal', 'International Sociology', 'Current Sociology', 'Innovation' and some on-line others have been screened; the abstracts of two recent conferences of the ISA and the ISA have also been screened. I've discussed the issue in question with some eminent foreign and Russian sociologists, biologists and geologists. I asked them to tell me their life-stories (actually, it had been the method of oral histories). The study of diaries and memoirs of D. Mendeleev, V. Vernadsky and other Russian eminent scientists who worked on the margin of social and natural sciences allowed me to understand their view on barriers between these two types of science.

Empirically, I've based on the secondary analysis of comparative researches on manenvironment interactions across the globe. In this respect my 15 years of participation in the UNESCOs 'Man and the Biosphere' program has been rather helpful. My interest has been concentrated on particular case-studies within the global context; it gave me an opportunity to reveal a maximum ties and interactions between all actors involved. In particular, the cruise and wreck of the Soviet 'Chelyuskin' ice-breaker in the 1934-34s and following rescue operations (within global context) had been analyzed, in particular, as an example of the USthe Soviet Union close cooperation. Then I've studied a set of critical situations (wildlife fires, floods, guerilla wars in cities) in Russia and abroad because I convinced that such situations are typical to current transition period.The analysis of activity of the grassroots, the NGOs and social movements has appeared very helpful because their actors have maintained connections with a rather wide circle of distant and unseen actors that are usually not taken into account in majority of current researches of globalization process. In the run of my all field-research I tried to maintain contacts with sociologists who worked on the same issues in the other parts of the world (in the US, the EU, Asia, Africa, and Australia). I undertook a special research project aimed at revealing the reasons why humanitarians, on the one side, and natural and technical scientists, on the other, were alienated and didn't trust each other. The oral histories gathering had been my favourite techniques. My family and professional roots allowed me to discuss the issues in question with some leading world and Russian humanitarians and scientists (U. Beck, M. Castells, R. Merton, V. Smirnov, D. Likhachev, P. Kapitsa, V. Ginzburg, A. Prokhorov, 0.J. Schmidt and many others). The careful study of diaries and memoirs of D. Mendeleev, V. Vernadsky and other Russian outstanding scientists who worked on the margin between social and natural sciences turned rather helpful as well. The 400 in-depths semistructured interviews with Russian and foreign environmental activists, both leaders and rankand-file activists, taken by me and my colleagues in the 1960-2010s allowed me to be in the midst of a set of socio-ecological conflicts in Russia and abroad. With an interval of about 10-15 years I'd send these interviews back to some my respondents asking them to comment (or to reconsider) their previous views and statements. The compilation of chronicles of the above conflicts allowed me to understand their integrated dynamics.

Combination of macro and micro analyses was one more key methodological principle. Actually, it has been the realization of well-known principle of the Greens called 'Think globally, act locally'. Therefore, my long-term studies of the evolution of a primary ecostructure (or the 'cocoon of the basic trust', using the A. Giddens formulae) has been of a no less important. Again, it has been a lucky chance that from the childhood I'd been deeply plunged into the atmosphere of discussions of the Arctic mastering, of non-stop flights from the USSR towards the US. My father supplied me with excellent books on how the Europeans mastered the both American continents, etc. The primary eco-structure concept had been developed by me in the end of 1980s [Yanitsky, 1988] in which its multi-level and interdisciplinary character had been shown. Recently my European colleagues issued a special 
number of 'The European Journal of Social Science Research' (2013), in which they analysed the transformations of privacy notion engendered by the hackers used modern ICtechnologies.

In parallel, I tried to reveal the situations in which all kinds of researchers do collaborated rather efficiently overcoming disciplinary and institutional barriers. Again, the experience of 'full-time integrator' work gained during participation in the above UNESO's program turned rather helpful. I carried out the study of some research projects aimed at understanding of such multisided processes as socio-ecological metabolism. Finally, I've screened the relevant literature both in Russian and English (Z. Bauman, U. Beck, M. Burawoy, R. Dunlap, A. Irwin, A. Giddens, S. Kravchenko, E. Rosa, M. Castells, R. Murphy, Z. Toshchenko, A. Touraine, J. Urry, D. Weiner, I. Wynne and many others). That screening had shown that the approach proposed by me may be considered as a kind of novelty. The screening of the ISA and the ESA recent international gatherings gave the same result. One existing method of interdisciplinary studies - the socio-ecological metabolism - is still mainly restricted to an energy flows, its circulation and use within man-made systems, and didn't include many other transformations within the SBT-systems. The coming of the 'internet of things' (K. Schwab) is the new challenge for the humanities because it will be the time when 'machines' could act without human control. Anyhow, the possible consequences of total socio-technical constructivism in all spheres of our life have to be carefully studied.

\section{Globalization challenges the humanities}

First, the growing domination of a new kind of technologically-integrated world over social order and everyday social life inevitably leads to substantial transformation in the humanities. They gradually lose their role of creator of values and moral norms, its public and political significance are shrinking, people lose their right to say, etc. The further the more, the global social order is becoming network-structured irrespectively to a particular social orders originated from a specificity of climate, landscape and modes of living of local communities and the states. All-embracing and all-penetrating character of global social order leads to the diminishing of social and cultural diversity. The role of this order creator is seized by the ICbased media, and the humanities are gradually turned into their junior partner by the making public opinion surveys and commenting their results. The 'golden age' of universities as a guiding intellectual force has passed, and the role of driving force of globalization has shifted into the hands of the Big business coupled with the Top bureaucracy. Accordingly, the significance of corps of great thinkers of the past, be they the philosophers, the writers or the politicians, in making public policy is slowing down.

The widespread of new technologies of communication and information generated the phenomenon of a 'space inversion'. It means not only a huge speeding up of the processes of exchange of all kinds of resources (material, informational and human), but the process of disappearing of a space as rather important factor of any social process. Accordingly, such notions as 'here' and 'there', 'close' and 'far', etc. acquired a relative character. Besides, the constellation of actual and virtual actors within a restricted space (area) may generate critical situations which, in turn, may produce high-level risks. Just that very case one could observe in Aleppo, Mosul and other cities of the Near East in which a city partisan war (a guerilla one) is in full swing. The transformation of such 'hot spots' into the 'black boxes' are going on, and the processes within them are out of control. More than that, such compression of various militants and peaceful peoples within a restricted area produces qualitatively new forms of critical areas [Yanitsky, 2014] which may be comprehend by joint efforts of various disciplines only. Such critical areas generate risks that could be then dispersed globally. The current influx of migrants into the EU has created a lot of such 'hot spots.' Their concentration in big cities 
doesn't necessarily mean spatial closeness. In the case of critical areas the two processes are simultaneously going on. The former is a Brownian motion: some desert to the enemy, others tries to escape from besieged city, still others continue to fight, etc. The latter is that the inhabitants turn into hostages or were forced to subordinate totally to the rules and rhythms of warfare.

\section{Turning point: The shaping of the SBT-systems}

The matter is that our planet has turned into a set of sociobiotechnical systems (the SBTsystems) of a various scale. The natural, social and technical structures and processes have merged into inseparable whole. It means that the habitual division on social, natural and technical sciences is no more fits to the new (integrated) reality. Any SBT-system is a supercomplex system structured in space and time. It's a true metabolic system which 'consists of' many different interactions: of use, cooperation, merging, annihilation, etc., both internal and external. But in the final analysis, the SBT-essence is in its qualitatively transformative character, i.e. bio-chemical, socio-biological and so on and so forth. This thesis doesn't reject a capitalist character of the above metabolic transformations. The SBT-systems are the systems of production and exploitation of various resources. It may be resources produced by the SBTsystems themselves, gained from subaltern, i.e. local systems, or from the world ocean, cosmic space or from the heart of the Earth. In a manner, the global SBT-system may be qualified as permanently expanded system.

Therefore, any dichotomy approach like the 'man vs. nature', 'natural vs. socially constructed', or the 'safe vs. risky' are becoming conditional. Even if some areas seemed to us as absolutely natural they are in essence already turned into the SBT-systems by global turnover and sociobiotechnical metabolism. If people doesn't feel radiation it doesn't matter that it is not exist. The SBT-systems are not artificially constructed entities. On the contrary, they are internally interdependent, and the 'genetics' of such systems is of a hybrid character as well. Partly this genetics is conditioned by a hybrid nature of the SBT-systems, and partly it is created (constructed) by man. Of course, there is a hierarchy of the SBT-systems: they may be local, regional and global. But the essence of their variety is not in scale but in the very principle of their inner organization. Some of them are socially constructed in the frames of a certain territory, while others are network-structured across all local natural and social entities (ecosystems, communities, etc.).

All said above doesn't matter that such super-complex systems have never been studied. The best example is the concept of the Biosphere created by Russian geochemist and politician V. Vernadsky in 1920s [Vernadsky, 1980]. Another example is the process of globalization as such; one more case is an urban systems; and so on. But usually any particular discipline has been focused on its specific realm of interest, say, economic, sociological or technical ones. More often some disciplines were united when they pursue a practical aim, usually to construct kind of a machine or a PR-technology. In majority of other cases the academics prefer to study and teach their particular mono-disciplines. In my view, a qualitative specific of current globalization is in its all-embracing and all-penetrating character. It means that the globalization process is inherently of metabolic nature. In turn it means that the humanities are now faced with entirely new object of research which is complex, qualitatively different, and its mode of 'behavior' should be studied by joint efforts of a concert of sciences.

\section{Digitalization of humanities as a cultural threat}

Another possible threat of the Fourth Technological Revolution is the coming of total digitalization of human existence and its consequences. A qualitative shift is already in process: 
the digitalization is transforming from an instrument serving the current social processes (typing, printing, processing, storage and dissemination of information) into the mainstream of any forms of social life. Modern digitalization has many open and overt forms. One of it is growing codification of all spheres and forms of social life [Burawoy, 2008]. An endless diversity of forms of human activity is swiftly replacing by a restricted set of competences and protocols. One of the key issues of our times is a contradiction between a variety of rapidly changing situations in situ and an endless list of generalized rules of games. That is, a reflection, comprehension and self-organization are substituted by the choice within a given set of decisions (protocols). It's a real process of McDonaldization of social life.

Unfortunately, in current sociological researches the principle of taxonomy (hierarchical order) borrowed from the biology of plants took over the thorough analysis of a rather complex and nonlinear processes of transformation of global world. Taxonomic and typological approaches are the methods aimed at dividing of individuals into groups ranging by sex, age, type of residence, etc. Such approach actually means that a researcher is focusing on 'opinion groups' rather than on actual processes of competition, struggle, an emergence and disappearance of a variety of collective actors. Thus, the goals and diversity of their activity, interactions with other participants of a given process, and what is the most important, overall metabolism of a planet life is giving up. The reverse side of the same coin is all-embracing social constructivism (so called dramatizing a reality) fulfilled by the media magnate [Arsenault and Castells, 2008].

\section{Possible ways of modernization of the humanities}

The driving force of current globalization is natural and technological sciences. Humanities are not at the forefront, and this fact has negative consequences for all spheres of social and cultural life including a policy-making. A forthcoming risk of all-embracing movement towards replacement of any kind of social activity by the activity of smart machines should be carefully investigated. We have to keep in mind that the IQ of hackers and other criminals armed with modern IC-devices is permanently coming down, and a probability of global sudden disaster or an all-embracing risk is growing.

I realize that any cardinal turn in the humanities is rather difficult, and it will surely met the resistance from the part of existing social institutions accustomed to deal with particular disciplines. Besides, under economic crisis and overall 'turbulent' state of global community there are neither financial nor human resources at hand to launch such radical turn. Nevertheless, I'd remind, that the globalization process is multi-sided and multi-levelled. What is the way out? I suggest to move 'top-down', that is to focus humanities on critical experience of particular 'hot spots' (socially abandoned areas, urban wars, natural and man-made disasters as well as on all-encompassing threats to individual privacy) in which social, natural and technological processes are the most tightly compressed. And what is of a no less importance are accessible to a researcher. These micro and middle-range 'spots' are real hybrid phenomena, and scientific and political importance of their complex analysis is not still well comprehended. The studies of such 'spots' (or areas) may give a lot of useful knowledge on how exactly these qualitatively different processes turn into one another. But it is a hard labour aggravated by tough competition with media-constructed pictures of reality.

Another possible way of launching a process of interdisciplinary convergence and merging of natural, social and technical sciences is the study of an individual habit of mind and models of his/her everyday behaviour. It's again the case-study which is well-understandable to all branches of humanities and is needed in very modest resources. If we gain a bit more resources we may expand this type of problem-oriented interdisciplinary research on such well-known realm of integrated activity as a research project as such. I've already tested this 
method, and it gave very promising results. Let me remind that this approach named 'full-time integrators' had been successfully tested be me and my collaborators more than 25 years ago.

The third possible field of testing the processes of integrating of all kinds of sciences is to focus on grassroots and social movements which are by definition are included in a variety of ties and communicate with an endless amount of actors in all possible fields of human activity. The fruitfulness of the study of such actors has been shown by M. Castells [Castells, 1983] and then during the French-Russian research project 'New social Movements in Russia' (1991-94) under the guidance of prof. A. Touraine. Being involved in this project, I'd practically tested the method of 'Sociological Intervention' developed by Touraine and his colleagues. After then, an existence of local lore movements is ready-to-use example not only of integration of humanities, but of their interdependence with social practice and cultural life. Russian eminent historian, academician D. Lichachev, shoved it clearly. Any form of social activity is a kind of integration of territorial and communicative approaches. Actually, today there are two kinds of social and political geography: a territorially-based and a network-based. Accordingly, the modern geopolitics is neither geography, nor ideology. It's a form and method of mapping the struggle for resources and political domination. Any social actor shows an interest not to a particular area but he or she considers it as a resource for meeting some needs, material, cultural, educational and many others. Modern tourism is the best confirmation of integrated (multi-sided) interest in travelling. The last but not least case is an integrative process at micro-level. My 25-year experience in taking about 400 in-depth semi-structures interviews with Russian and foreign environmental activists and their counterparts allowed me to be in the midst of multi-sided local-global conflicts and to develop the concept of an individual's primary eco-structure in the past, present and future time dimensions [Yanitsky, 2012]. In particular, these interviews showed a relativity of the 'subject-environment' opposition and confirmed my idea of transforming an environment into actor if a certain threshold of environmental carrying capacity would be overcome. But how an individual's existence in two spaces, 'material' and 'virtual', are interrelated is one more challenge to humanities. Unfortunately, the humanities still consider a virtual world as an instrument of prompt gaining information than as the space of a man's existence.

It may seem that all said above is so difficult to implement and will take much time and other resources. But it's not correct. The first step on the interdisciplinary way is rather simple. Look, the prevailing method of research in humanities is public opinion survey. That is, a kind of distant observation without any contact with other actors of all kinds. This old tradition should be buried. A real life is an endless man's interaction with myriad of actors, tangible and intangible. For example, if you don't feel a radiation flow, it doesn't mean that it's not exists. Our life is totally depends on magnetic fields, X-rays, biochemical metabolic processes, etc. But first of all, a humanitarian should be in the midst of social life. He/she have to study its variety of tempo-rhythms, and to try on himself, how to live in such 'melting pot.' And in parallel, a researcher should distance from the object of his/her interest.

It seems to me that we are needed in joint efforts of all branches of sciences and humanities to learn how they do understand each other in such critical (mobilizing) cases. The recent merging of two international organizations, the UNESCO's the ISSC and the ICSU dividiond, gives the good signal. The coming global warming is a warning if we remain divided by institutional walls. Within the frames of existing institutional structure of science the distance between real globalization and its multi-sided scientific comprehension is growing. The higher institutional barriers are between disciplines and institutions, the longer the process of decision-making. Therefore, recent research politics should be problem-oriented and 
interdisciplinary in character. Finally, any processes of learning should be subjected to the problem-oriented and interdisciplinary approaches. These principles should become a norm of teaching and self-education in any age but better from the early childhood. The Enlightenment system of cutting current reality on disciplinary 'pieces' should be reconsidered. A flow of current reality is inseparable and permanently increases its speed.

\section{CONCLUSION}

Globalization generated by new scientific and technological revolution put forward the issue of modernization of humanities. The technological development outstrips its humanitarian comprehension and political regulation. Recently this gap has become critical. The humanities should master not only the changes produced by achievements in particular disciplines but to comprehend a qualitatively new state of the world as such which I've called the sociobiotechnical system (the SBT-system). Accordingly, modern institute of knowledge production is in the run towards new phase of a double-sided process: the further differentiation of scientific disciplines and social practices and their growing interdependence.

A necessity of such integration is conditioned by growing unfitness of a majority of current researches in Humanities to a highly complex, nonlinear and risky globalization process accompanied by twists, bifurcations, and unintended consequences. Modern globalization is inherently contradictory process. It's a mixture of developmental and regressive trends. The further development of global network structures is run against territorially-based social entities (the communities, states and their alliances). Actually, these trends are the two sides of the same coin, and their struggle is shaping critical areas not suitable for human life across the globe.

Epistemologically, there are three main approaches to the study of globalization process: our planet is an unstable and contradictory but it is the wholeness with its own mode of behaviour; the nature, man and its technical devices may play a role of an actor, or an environment, and humanitarians should follow these actors. That is, the development of humanities should go hand in hand with evolution of global SBT-system. And research techniques (instruments) must fit to this dynamics.

An approach to any study of globalization process has to maintain the 'follow the actor' principle. Historical methods and the making of global scenarios are as important as the study of particular cases 'here and now' giving an opportunity to see a macro into a micro, and vice versa. A view of an insider who is within the midst of a clash of adversaries is as important as perception of a by-stander observer who is capable to compare this very case with some other across the world. Any humanitarian should remember that the next phase of Technological revolution is coming, and the humanity is on the eve of an era of the 'internet of things' based on self-programming robotized systems. A degree of integration of humanities and their interpretation of achievements of natural and technical sciences should resemble the integrative character of modern world. The 'science-social life-political action' communication should be studied at all levels of human existence and the SBT-functioning.

\section{FUNDING}

This article received no specific grant from any funding agency in the public, commercial, or not-for-profit sectors.

\section{References}

Arsenault A. and Castells M. (2008) Switching Power: Rupert Murdoch and the Global Business of Media Politics. International Sociology 23(4): 488-513.

Bauman Z. (2004) Wasted Lives. Modernity and its Outcasts. Cambridge, UK: Polity Press. 
Bauman Z. (2011) 44 Letters from Liquid Modern World. Cambridge: Polity Press.

Bauman Z. (2011a) Collateral Damage. Social Inequalities in a Global Age. Cambridge: Polity Press.

Bauman Z. (2011b) Culture in a Liquid Modern World. Cambridge: Polity Press.

Beck U. (1992) Risk Society. Toward a New Modernity. London: SAGE.

Beck U. (1999) World Risk Society. Malden, MA: Polity Press.

Beck U. (2007) Cosmopolitan Version. Cambridge: Polity Press.

Beck U. (2015) Emancipatory Catastrophism: What does it mean to Climate Change and Risk Society? Current Sociology, 63 (1): 75-88.

Budyko M. (1977) Global'naya ekologiya [Global Ecology]. Moscow: Mysl' (in Russ.).

Burawoy M. (2008) What is to be Done? Theses on the Degradation of Social Existence in a Globalizing World. Current Sociology, 56 (3): 351-359.

Burawoy M. (2015) Facing the unequal world. Current Sociology, 63 (1): 5-34.

Capra F. (1982) The Turning Point. Science, Society and the Rising Culture. Toronto, New York, London: Bantam Books.

Castells M. (1983) The City and the Grassroots. A cross-cultural Theory of Urban Social Movements. London: Edward Arnold, Ltd.

Castells M. (2010) The Information Age: Economy, Society and Culture. Vol. I: The Rise of Network Society. $2^{\text {nd }}$ Edition. Oxford: Willy-Blackwell.

Catton W. R. Jr., and Dunlap R. E. (1980) A New Ecological Paradigm for Post-Exuberant Sociology, American Behavioral Scientist, Vol. 24 (1): 15-47.

Chizevskiy A. (1926) Fizicheskie Faktory Istoricheskogo Processa [Physical Factors of a Historical Process]. Kalyga: Pervaya gostipolitografiya (in Russ.).

Chizhevsky A. (1964) Zemnoye Echo Solnechnych Bur' [The Earth Echo of Sun Storms]. Moskva: Mysl' (in Russ.).

Fisher-Kowalski M. (1997) Society's Metabolism: On the Childhood and Adolescence of a Rising Conceptual Star, in Redklift M. and G. Woodgate, eds. The International Handbook of Environmental Sociology. Northampton, MA: Edward Elgar, pp.119-137.

Fisher-Kowalski M. and H. Haberl. (2007) Socioecological Transitions and Global Change. Trajectories of Social Metabolism and Land Use. Vienna: Klagenfurt University.

Giddens A. (2009) The Politics of Climate Change. Cambridge: Polity Press.

Ionin L. (2007) Sotsiologiya v obshchestve znanyi. Ot epochi moderna k informatsionnomu obshchestvu [Sociology in Knowledge Society. From modern epoch towards informational society]. Moscow: Publishing House SU VSE (in Russ.).

Irwin A. and Wynne B., eds. (1996) Misunderstanding Science? The Public Reconstruction of Science and Technology. Cambridge: Cambridge University Press.

Keen D. (2008) Complex Emergences. Cambridge: Polity.

Lidskog R., Mol A. and Oosterver P. (2015) Towards a Global Environmental Sociology? Legacies, Trends, and Future Directions. Current Sociology, 63 (3): 339-368.

Martinez-Alier J. (2009) Social Metabolism, Ecological Distribution Conflicts, and Languages of Valuation, Capitalism Nature Socialism, 20 (1): 58-87.

Milbrath L. (1984) Environmentalists: Vanguard for a New Society. Albany: State University of New York Press.

Phillips B. 2009 Disaster Recovery. Boca Raton, London, New York: CRC Press (Taylor \& Francis Group).

Prades J. (1999) Global Environmental Change and Contemporary Society. International Sociology, 14 (1): 7-31.

Prigogine I. and Stengers I. (1984) Order out of Chaos. London: Heinmann.

Sundar N. (2014) In the times of Civic War: On being a Schizophrenic (public) Sociologist. Current Sociology, Vol. 62 No 2, Monograph 1, March: 168-180. 
Touraine A. (1988) Return of the Actor. Social Theory in Postindustrial Society. Minneapolis: University of Minnesota Press.

Urry J. (2003) Global Complexity. Cambridge: Polity Press.

Urry J. (2005) Complexity. Theory, Culture and Society. Special Issue, No 22.

Urry J. (2008) Mobilities. Cambridge: Polity Press.

Urry J. (2012) Climate, Change \& Society. Cambridge: Polity Press.

Van Holdt K. (2014) Critical Engagement in Fields of Power: Cycles of Sociological Activism in Post-apartheid South Africa. Current Sociology, Vol. 62, No 2 Monograph 1, March: 181-196.

Vernadsky V. (1980) (first edition 1922). Problemy biogeochimii. Trudy biogeochimicheskoi laboratorii. Vypusk XVI. Moskva: Nauka [Geochemical problems. Works of Biogeochemical Laboratory]. Issue XVI, Moscow: Nauka (in Russ.).

Waters M. (1995) Globalization. Lnd. \& N.Y.: Routledge.

Wolman A. (1965) The Metabolism of the Cities. Scientific American, 213 (3): 178-93.

Yanitsky 0. (1988) Towards Creating a Socio-Ecological Conception of a City, in Cities and Ecology. The International Expert Meeting. Souzdal, Sept. 24-30, Moscow: Centre of International Projects, pp. 54-57.

Yanitsky 0. (2004) Risk-solidarities: The Russian Version. Inter. 2-3: 155-63.

Yanitsky 0. (2012) A Primary Eco-Structure: The Concept and its Testing. Social Analysis, 2 (2): 7-24.

Yanitsky O. (2012a) The 2010 Wildfires in Russia. An Ecosociological Analysis. Sociological Research, 51 (2): 57 75.

Yanitsky O. (2013) Metabolicheskaya konseptsiya sovremennogo goroda [Metabolic Concept of a Modern City]. Sotsiologicheskaya nauka i sotsial'naya praktika] 3: 16-32 (in Russ.).

Yanitsky 0. (2014) Ekologicheskyi archiv Olega Yanitskogo [Ecological Archive of Oleg Yanitsky]. Available at: www.isras.ru/publ.html?id=2983 (in Russ.).

Yanitsky O. (2014a) Sociology of Critical Areas. Open Journal of Social Science Research. 2 (3): 112-118. Available at: http://manuscript.sciknow.org/uploads/ojssr/pub/ojssr_ 140963345.pdf

Yanitsky 0. (2015) Are the Sociologists well prepared to the Modern War? Available at: http://cirworld.com/journals/index.php/jssr/article/view/3680/pdf_99

Yanitsky O. (2016) New Developments in Environmental Sociology. Available at: http://www.isras.ru/publ.html?id=4308 07/06/2017 